\title{
Correlates of protection against human rotavirus disease and the factors influencing protection in low-income settings
}

\author{
E Clarke $^{1}$ and U Desselberger ${ }^{2}$
}

Rotaviruses (RV) are the leading cause of gastroenteritis in infants and children worldwide and are associated with high mortality predominately in low-income settings. The virus is classified into $G$ and $P$ serotypes and further into $P$ genotypes based on differences in the surface-exposed proteins VP7 and VP4, respectively. Infection results in a variable level of protection from subsequent reinfection and disease. This protection is predominantly homotypic in some settings, whereas broader heterotypic protection is reported in other cohorts. Two antigenically distinct oral RV vaccines are licensed and are being rolled out widely, including in resource-poor setting, with funding provided by the GAVI alliance. First is a monovalent vaccine derived from a live-attenuated human RV strain, whereas the second is a pentavalent bovine-human reassortment vaccine. Both vaccines are highly efficacious in high-income settings, but greatly reduced levels of protection are reported in low-income countries. Here, the current challenges facing mucosal immunologists and vaccinologists aiming to define immunological correlates and to understand the variable levels of protection conferred by these vaccines in humans is considered. Such understanding is critical to maximize the public health impact of the current vaccines and also to the development of the next generation of RV vaccines, which are needed.

\section{INTRODUCTION}

Rotaviruses (RV) are a leading cause of acute, often dehydrating gastroenteritis in infants and young children worldwide. Irrespective of the socioeconomic setting, virtually all children will have been infected with RV by between 2 and 3 years of age, with the age of first infection generally being lower in lowincome countries. Recent estimates suggest that the infection is responsible for over 450,000 deaths per year in children under the age of 5 , with the greatest burden of mortality being focused in a small number of low-income countries in sub-Saharan Africa and South-East Asia. ${ }^{1-5}$

\section{CLASSIFICATION AND STRAIN DIVERSITY}

RV are non-enveloped, icosahedral particles, which are composed of three layers (Figure 1). The outer capsid layer consists of VP7, a glycoprotein, and the protease-sensitive VP4, which forms protruding spikes. Both proteins elicit neutralizing antibodies. The intermediate layer is made up of the major structural protein VP6. The core is composed of VP2 (the scaffolding protein) with VP1 (the viral RNA-dependent RNA polymerase), and VP3 (the capping enzyme), attached on the inside. The core encloses the 11 genomic segments of double-stranded RNA. The genome encodes six structural proteins (VP1-VP4, VP6, and VP7) and 5/6 non-structural (NS) proteins, NSP1-NSP5/6. ${ }^{6}$

Through proteolysis, VP4 is cleaved into two fragments termed VP5 ${ }^{\star}$ and VP8 ${ }^{*}{ }^{7}{ }^{V P} 8^{*}$, which forms the head of the VP4 spike, interacts with receptors on host cells and is required for virion attachment and hence RV infection. ${ }^{7,8}$ Specifically, $\mathrm{VP} 8^{\star}$ of the major human $\mathrm{RV}$ interacts with human histo-blood group antigens (HBGA), expressed on mucosal epithelial cells and other cell types, leading to the possibility that genetic and developmental variation in HBGA expression may result in variable susceptibility to infection with different RV strains (Figure 2). ${ }^{9-11}$

$\mathrm{RV}$ is classified serologically into at least seven species, also termed 'groups' (A to $\mathrm{G}(\mathrm{H})$ ) based on antigenic differences and gene diversity of VP6. ${ }^{12,13}$ The majority of disease in humans worldwide is caused by group A RV, which are further divided

${ }^{1}$ MRC Unit, The Gambia, Banjul, The Gambia and ${ }^{2}$ Department of Medicine, University of Cambridge, Cambridge, UK. Correspondence: E Clarke (eclarke@mrc.gm) Received 15 March 2014; accepted 16 October 2014; published online 3 December 2014. doi:10.1038/mi.2014.114 


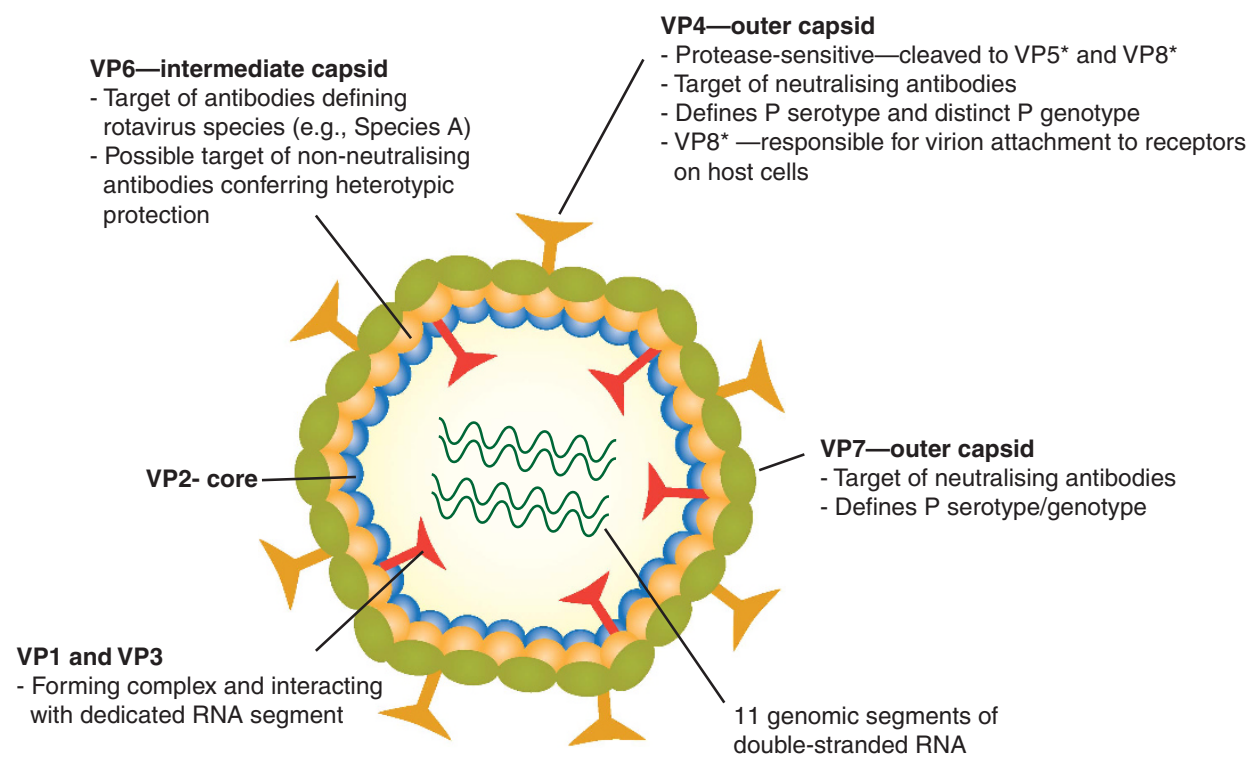

Figure 1 Structure of the RV triple layer particle illustrating the known and potential targets of neutralizing antibodies. VP4 defines the P serotype and distinct $\mathrm{P}$ genotype and is the target of P-type-specific (homotypic) neutralizing antibodies. VP7 defines the G serotype/genotype and is the target of G-type-specific (homotypic) neutralizing antibodies. Conserved epitopes of both VP4 and VP7 may, in addition, be responsible for elements of the heterotypic protection. VP6 defines the RV species. High levels of anti-VP6 antibodies are detected in humans following infection and vaccination and may confer heterotypic protection (see also Figure 2).

into subgroups I and II. Antibodies against VP7 define the G serotype, which is synonymous with the G genotype. Antibodies against VP4 define the P serotype, although, as more $\mathrm{P}$ genotypes have been reported than $\mathrm{P}$ serotypes, the two are reported separately. Thus, a particular A RV may be defined by its G serotype/genotype, its P serotype, and P genotype as, for example, G1P1A. ${ }^{6,8,14}$

More than 70 combinations of VP7 and VP4 types have been identified in RV infecting humans, although the combinations G1, G3, G4, and G9 with P1A[8] and G2 with P1B[4] represent around three quarters of strains circulating in humans worldwide. ${ }^{14,15}$ However, a recent meta-analysis of the RV co-circulating in Africa suggests that the common RV strains mentioned above represent only one-third of the isolates, causing disease in this setting. Indeed, RV diversity appears to be very high in Africa, which is likely to reflect genome reassortment between co-infecting RV as well as zoonotic transmission events. ${ }^{14,16}$ However, a whole-genome-based classification system has now been established. ${ }^{17,18}$ Using this system, only two major genotype constellations ( 1 and 2 ) of the non-G, non-P-encoding genes appear to be present in the majority of RV circulating in humans, suggesting that the genetic diversity of A RV infecting humans may, in fact, be more limited than previously assumed. ${ }^{19}$

\section{IMMUNITY TO ROTAVIRUS}

Although the nature of the immune response generated by RV infection (and vaccination) has been studied in detail in animal models, mostly in infant or adult mice and gnotobiotic piglets (reviewed in refs 20,21), correlates of protection, and the underlying cellular responses against RV in humans remain incompletely understood. RV-specific antibodies, especially of the immunoglobulin (IgA) class, are recognized as being important. ${ }^{22}$ However, the efficiency of antibody transfer into the gut varies between species and also with the age of an animal. For example, in mice IgA is actively transported in the bile, whereas in humans this is not thought to be the case. ${ }^{20}$ Similarly, mice are only susceptible to RV disease for the first 15 days of life, making it difficult to meaningfully evaluate the mechanisms underlying homotypic and heterotypic immunity from disease in this species, although an infection rather than disease adult model has been used extensively. ${ }^{23,24}$ Differences in the reactivity of different animal and human RV strains further preclude the drawing of firm conclusions regarding human protection based on animal data. Anti-VP6 antibodies have a partially protective effect in mice, ${ }^{25}$ whereas they are not protective in piglets despite their local production in the gut. ${ }^{26}$ Consequently, although the use of animal models to study RV disease and immunity has played a critical role in current understanding, the effective application of the latest techniques in the immunologist's toolbox to studies of RV immunity in human infants must be the current goal.

\section{PROTECTION FOLLOWING NATURAL INFECTION}

Available human data indicate that the immunity induced by natural RV infection, while not sterilizing, can protect from symptomatic disease. Furthermore, protection does not appear to depend on whether the primary infection was symptomatic or asymptomatic. This is significant as up to three quarters of infections in children between 6 and 24 months of age have been shown to occur asymptomatically, and this figure appears even higher in those below the age of 6 months. ${ }^{27-30}$ 
1. Rotavirus virion attachment to histo-blood group antigens expressed on the mucosal epithelium

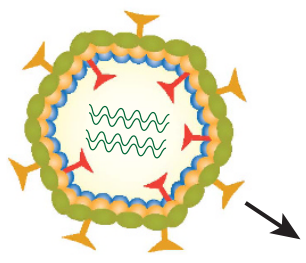

$\alpha-1-2$ fucosylated carbohydrate

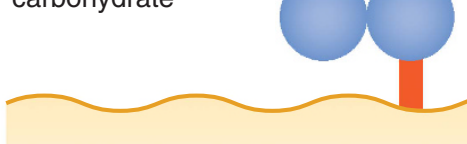

Mucosal epithelium
2. Genetic polymorphisms or developmentally regulated expression of histo-blood group antigens
3. Blocking antibodies

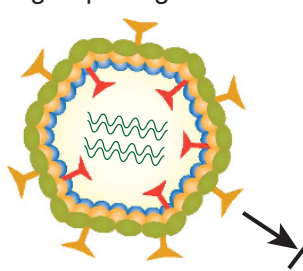

Human blood group antigen

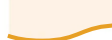

Figure 2 VP8 and human blood group antigen (HBGA) interaction. (1) Certain human RV bind to HBGA expressed in mucosal epithelial cells through the interaction of VP8* with $\alpha$ 1-2 fucosylated carbohydrate motifs in the HBGA. (2) Genetic polymorphisms in genes responsible for the addition of such carbohydrate motifs (e.g., the FUT2 gene) may be responsible for resistance to symptomatic VP8-type-specific RV infection. Similarly, developmentally regulated expression may confer resistance to infection in certain groups (e.g., newborns). Both these effects remain to be conclusively demonstrated although are an avenue of exploration. (3) It has also been hypothesized, based on findings with norovirus, that RV antibodies may block RV-HBGA interaction and thus preventing virion attachment and playing a role in heterotypic RV protection.

When assessing protection, recent data regarding potential underlying genetic and developmental susceptibility to infection with a given RV strain should be considered (Figure 2). Thus, for example, in a retrospective study, a common polymorphism in the FUT2 gene, which blocks the synthesis of $\alpha 1,2$ fucosylated carbohydrates on HBGA, appeared to result in resistance to symptomatic $\mathrm{p}[8] \mathrm{RV}$ infection. ${ }^{11}$ This may reflect a loss of the interaction between $\mathrm{VP}^{*}$ from $\mathrm{P}[8] \mathrm{RV}$ and the HBGA on mucosal epithelium, which has been shown to occur in vitro. ${ }^{31}$ Similarly, it has been hypothesized that developmentally regulated expression of specific carbohydrate moieties on HBGA may be responsible for the predisposition of neonates to infection with $\mathrm{P}[11] \mathrm{RV},{ }^{9,32}$ although the importance of these finding in vivo are yet to be determined.

In Mexico, infants followed from birth until 2 years of age were shown to be completely protected from moderate-tosevere diarrhoea, defined using the Vesikari score ${ }^{33}$ following two episodes of infection. ${ }^{28}$ In contrast, in a study conducted in India, $>80 \%$ protection was conferred against the same severity of illness by three infections. ${ }^{34}$ Protection was predominantly although not exclusively against the homotypic strain in the former cohort, while there was no evidence that protection was homotype-specific in the study in India. ${ }^{28,34}$ In Guinea-Bissau, a single infection was shown to protect two-thirds of infants from reinfection during the same epidemic, but only around one-third remained protected in subsequent epidemics. Whether this represented waning immunity or the effects of inter-epidemic strain variation was not determined. ${ }^{30}$
RV infection during the first 14 days of life has been shown to reduce the severity but not the frequency of subsequent episodes of gastroenteritis in an Australian study. ${ }^{35}$ In contrast, infection with a bovine-human reassortment G10P[11] RV, initially described in asymptomatic neonates in India, but subsequently shown to cause symptomatic disease, appeared of confer little protection in the largest studies conducted to date although may provide a degree of protection in certain settings. ${ }^{36-40}$ Thus, at least beyond the neonatal period, RV infection, whether symptomatic or asymptomatic, has been shown to protect against subsequent symptomatic disease. The protection conferred is variable and is predominantly homotypic in some but not in other cohorts. It remains to be determined whether this variability reflects solely differences in the inoculum size of the subsequent RV challenge in different settings or differences in the level of immunity generated by natural infection in these different population groups.

\section{CORRELATES OF PROTECTION FOLLOWING NATURAL INFECTION}

In the context of vaccine development, correlates of the protection induced by natural infection have been studied, although absolute correlates remain elusive..$^{21,41,42}$ Data regarding the RV-type-specific neutralizing antibody titres induced by infection suggest that the degree of cross-protection conferred does not depend solely on the RV serotype. ${ }^{21,43}$ Furthermore, initial exposure to RV induces a predominantly homotypic antibody response, whereas broader heterotypic responses are induced by repeated exposure, even if the 
individual infections themselves comprise of only a restricted number of G-types. ${ }^{21,44}$ This suggests that responses are first primed against the surface exposed VP7 and VP4 epitopes, whereas only on repeated exposure are antibodies induced against either non-neutralizing, conserved epitopes of the same proteins or against entirely different $\mathrm{RV}$-encoded proteins. In addition, although $\mathrm{RV}$ infection originates in the intestinal mucosa, both antigenaemia and viraemia frequently occur in children with RV gastroenteritis and thus, systemic as well as a mucosal immune responses are induced. ${ }^{45-47}$

In an early study conducted in a Japanese orphanage, neutralizing antibody titres of greater than 1:128 appeared to be protective against homotypic RV gastroenteritis, although heterotypic G1 and G4 responses were also induced despite the infections themselves being solely due to a G3 strain. ${ }^{48}$ In a case-control study conducted in Bangladesh, children developing RV-associated diarrhoea had significantly lower baseline homotypic as well as heterotypic neutralizing antibody titres than age-matched controls although, of note, only heterotypic antibody levels were associated with protection on multivariant analysis. ${ }^{49}$ In a cohort of 200 infants in Mexico, a serum anti-RV IgA titre of greater than 1:800 offered around 80\% protection against $\mathrm{RV}$ disease. ${ }^{50}$ The same titre offered complete protection against MSD, although even titres of greater than 1:6400 were not sterilizing. In the same study, serum IgG titres of greater than 1:6400 offered $50 \%$ protection against RV infection. Higher IgG titres did not increase the level of protection and IgG did not appear to offer significant protection against disease. ${ }^{50}$ In contrast, a study conducted in Texas reported that not only IgA but also IgG titres correlated with reductions in both infection and diarrhoea. ${ }^{51}$ In a Danish study, neither IgA nor IgG titres in the serum influenced the frequency of diarrhoea associated with infection, although the IgA titres did reduce disease severity. ${ }^{52}$ The authors of this study also demonstrated a correlation between serum $\operatorname{IgA}$ bound to the secretory fragment (RV-SIg) and duodenal IgA, suggesting that this fraction of the serum IgA was intestinal in origin. ${ }^{53}$ Although healthy breast feeding infants have RVSIg-transferred in breast milk-in the duodenum and stool, the antibody is only detected in the serum following infection. ${ }^{54}$ Consequently, available data suggest serum-neutralizing antibody and IgA titres are associated with a degree of protection from RV and also that the latter may reflect the induction of local immunity in the intestine.

A number of studies have gone on to examine the protective effect of RV-specific copro-IgA in the stool directly. Although RV infects the small intestine, fecal IgA has been shown to consistently predict the IgA levels in the duodenum and, as such, can be used as a surrogate for the antibody present at this site. ${ }^{55}$ Data from adult challenge studies suggested that fecal IgA decays more rapidly than antibody in the serum. ${ }^{56}$ In a study undertaken in the United States, the levels of copro-IgA in children under 18 months of age who were exposed to RV within the environment of a day-care centre, and who went onto develop infection, were significantly lower at baseline than in those who remained un-infected. Similarly, the symptomatic, infected group had lower titers than the asymptomatic infected children. ${ }^{57}$ A study in Australia also demonstrated an inverse relationship between the level of RV-specific copro-IgA and the likelihood of developing symptomatic disease associated with infection. ${ }^{58}$ Although infection has been shown to boost fecal antibody titres, in a study following children who developed a second RV infection in the same season, fecal antibody levels were shown to have returned to near baseline in the 2-4-month period between infections, reinforcing the relative transience of the copro-IgA response. Furthermore, at an individual level, high titres do not ensure that a child is protected or that an infection will be asymptomatic, and similarly not all children with low titres will develop symptomatic disease after exposure. Thus, even at the level of local humoral immunity, the correlation is inconsistent. ${ }^{57}$

The protective effect of maternal antibodies, transferred to the infant either across the placental or in breast milk has also been explored. The peak incidence of diarrhoea associated with RV infection occurs at between 7 and 15 months of age dependent on setting. In the first two month of life as few as one in five infants with RV infection develop symptoms and infections in neonates are commonly asymptomatic. ${ }^{59}$ In contrast, $60 \%$ of infections have been shown to be symptomatic between 9 and 14 months of age. ${ }^{30}$ In a study conducted in India, over one-third of newborns shed RV in their stool over the first $72 \mathrm{~h}$ of life and, in infants remaining in hospital for 5 days or more, this figure rose to well over two-thirds. Despite these remarkable rates of viral shedding, less than one-fifth of those studied developed symptoms and these were generally mild. ${ }^{60}$ Although not proven, these data suggest a protective effect for maternal antibodies in the newborn period. More specifically, in studies conducted across Mali, Kenya and Ghana, high G1, G2, G3, G4, and P1-neutralizing antibody titres have been reported in unvaccinated infants, and have been taken to reflect the passage of antibodies across the placenta. ${ }^{61}$ In addition, their protective effect against homotypic RV strains has been demonstrated in some studies, whereas in other cohorts the level of neutralizing antibodies in cord blood appear to confer no protection. ${ }^{60,62}$

RV-specific IgA $A^{54,63-70}$ and neutralizing antibodies ${ }^{64-70}$ are also present in breast milk. The levels are at their highest in colostrum and fall significantly as breast feeding is established. ${ }^{54,65,67,68}$ In a case-control study conducted in rural Bangladesh, exclusive breast feeding offered significant protection against severe rotavirus gastroenteritis over the first year of life, although there was no overall reduction in disease over the 2 -year follow-up period, and any association with antibodies in the breast milk was not investigated. ${ }^{71}$ In a study in India, the breast milk IgA titres in the mothers of infants who became infected with RV in the first 5 days of life were significantly lower than the titres present in those who remained uninfected over the same period. ${ }^{63}$ In a study conducted in Mexico, no difference in the breast milk-neutralizing antibody titres was demonstrated between infant infected with RV over the first year of life and those who remained uninfected. ${ }^{69}$ In addition, non-antibody components of breast milk including both lactoferrin and lactadherin have been shown to possess 
$\mathrm{RV}$-neutralizing capacity and may be responsible for some of the protection conferred by breast feeding in certain settings. ${ }^{66,68}$

\section{CURRENT ROTAVIRUS VACCINES}

Despite the lack of an established correlate of the protection generated by infection, two, antigenically distinct live-attenuated, oral RV vaccines have been licensed since 2006. The monovalent Rotarix (RV1) contains an attenuated human G1P1A[8] RV strain and is given as a two-dose schedule in infancy. ${ }^{41}$ In contrast, Rotateq (RV5) is a pentavalent vaccine composed of five bovine-human mono-reassortment strains containing genes encoding the human G1, G2, G3, G4 and $\mathrm{P} 1 \mathrm{~A}[8]$ antigens along with the genes encoding the bovine G6 and P7[5] proteins and all other bovine RV proteins. All the $\mathrm{P}$ and $G$ gene products induce neutralizing antibodies, and therefore, the vaccine may more accurately be considered to be heptavalent. ${ }^{41}$ The vaccine RV5 is given as a three-dose schedule. ${ }^{41}$ In 2009, the Strategic Advisory Group of Experts on Immunization at the $\mathrm{WHO}$ recommended that $\mathrm{RV}$ vaccination should be included in the national immunization schedules of all member states. These recommendations were reinforced in January 2013, and the vaccines are now being increasingly used worldwide, having been made available to eligible countries through the GAVI Alliance. ${ }^{72-75}$

\section{PROTECTION INDUCED BY VACCINATION}

Despite such progress, important questions remain regarding both the correlates and determinants of the protection induced by $\mathrm{RV}$ vaccines, given that their efficacy appears to depend, at least in part, on the socioeconomic status of the countries in which studies have been conducted. ${ }^{22,73,76-78}$

Details of the efficacy trials undertaken for RV1 are summarized in Table 1. In trials conducted in the highincome settings of Hong Kong, Singapore, Taiwan, and Japan, as well as in a trial conducted across six European countries, the vaccine consistently provided greater than $95 \%$ protection against severe diarrhoea over the first year of life and greater than $90 \%$ protection up to the end of the second year. ${ }^{79-83}$ In both Hong Kong and in Europe, efficacy of greater than 95\% against homotypic G1-containing strains was maintained up to the end of the second year, whereas a minimum of $85 \%$ protection against strains expressing other G-types was reported over the same period. ${ }^{79-81}$ In studies conducted in middle-income countries of Latin America and also in Finland, the same vaccine provided between 80 and $85 \%$ protection against severe RV diarrhoea over the first year of life and 80\% protection up to the end of the second year. ${ }^{84-86}$ In these studies, comparable levels of protection were demonstrated against either G1 strains or $\mathrm{P}[8]$-expressing strains although protection against a heterotypic G2P[4] strain was not consistently demonstrated in these studies. ${ }^{84-86}$

In contrast to these figures, trials of the same vaccine conducted in the low-income settings of South Africa and Malawi reported efficacies, against severe RV gastroenteritis of $<75 \%$ in South Africa and $<50 \%$ in Malawi over the first year of life following the standard two-dose regimen. ${ }^{78,87}$ There was no evidence of ongoing protection in the second year of life in either country, and overall, the efficacy over the first 2 years of life was consequently below $35 \% .{ }^{87,88}$ In both cases, data suggested the efficacy of a three-dose regimen was likely to be greater in the second year of life. ${ }^{87,88}$ Although G1 strains were significantly underrepresented in Malawi, the difference in efficacy at year 1 remained even when the protection conferred against G1 strains was examined in isolation, suggesting that strain diversity was not solely responsible for the difference. Indeed, in both Malawi and South Africa, homotypic protection against G1 strains, at $43 \%$ and $69 \%$ respectively, was lower than the $50 \%$ and $85 \%$ protection reported against heterotypic nonG1-expressing strains. ${ }^{78,87-90}$

The efficacy of RV5 has similarly been examined in trials conducted in a number of different settings, the details of which are provided in Tables 2 and 3. In studies conducted in the high- and middle-income countries of Europe, North American, and Latin America, RV5 reduced severe RV gastroenteritis caused by homotypic G1, G2, G3, and G4 strains by $98 \%$ in the first RV season and by $88 \%$ in the subsequent season. ${ }^{91}$ In the same setting, greater than $90 \%$ protection against either hospitalization or the requirement for emergency department review was demonstrated following vaccination..$^{92}$ A comparable trial of RV5 conducted in Vietnam and Bangladesh, middle- and low-income settings, respectively, reported an efficacy up to 2 years of age of $64 \%$ against severe gastroenteritis in Vietnam and under $43 \%$ in Bangladesh. ${ }^{77}$ Here again, as $100 \%$ of strains were covered by the vaccine in Vietnam and $92 \%$ in Bangladesh, circulating heterotypic viruses did not explain either the low or differential efficacy reported. ${ }^{42,77}$

Trials of RV5 conducted in the low-income settings of Ghana, Kenya, and Mali reported a cumulative vaccine efficacy against severe RV gastroenteritis of just below $40 \%$ percent over 2 years of follow-up. Although $\sim 65 \%$ protection was demonstrated over the first year of life, this figure fell to under $20 \%$ over the second year of life. ${ }^{42,93}$ However, overall, the efficacy of the vaccine was between $55 \%$ and $65 \%$ in Ghana and Kenya, but was $<20 \%$ in Mali despite $97 \%$ of the circulating strains being homologous in Mali compared with $78 \%$ and $89 \%$ in Ghana and Kenya, respectively. ${ }^{93,94}$ In addition, although the number of heterologous infections was low, when the combined data from the three countries was analyzed, vaccine efficacy against severe diarrhoea caused by $\mathrm{RV}$ expressing $\mathrm{G}$ and $\mathrm{P}$ types contained within the vaccine was $34 \%$ compared with an efficacy against non-vaccine G-types of over $81 \%$ and non-vaccine P-types of over $40 \% .{ }^{95}$

Following the introduction of these vaccines, such variable efficacy data have translated into differences in vaccine effectiveness, which similarly appear to be context-dependent (Table 4). Thus, in case-control studies undertaken in the United States, Australia, and Israel, RV5 had a demonstrated effectiveness of between 85 and $90 \%$ in preventing hospitalization or emergency department attendance over the first year of life. ${ }^{96-98}$ Similarly, studies undertaken in Brazil following RV1 


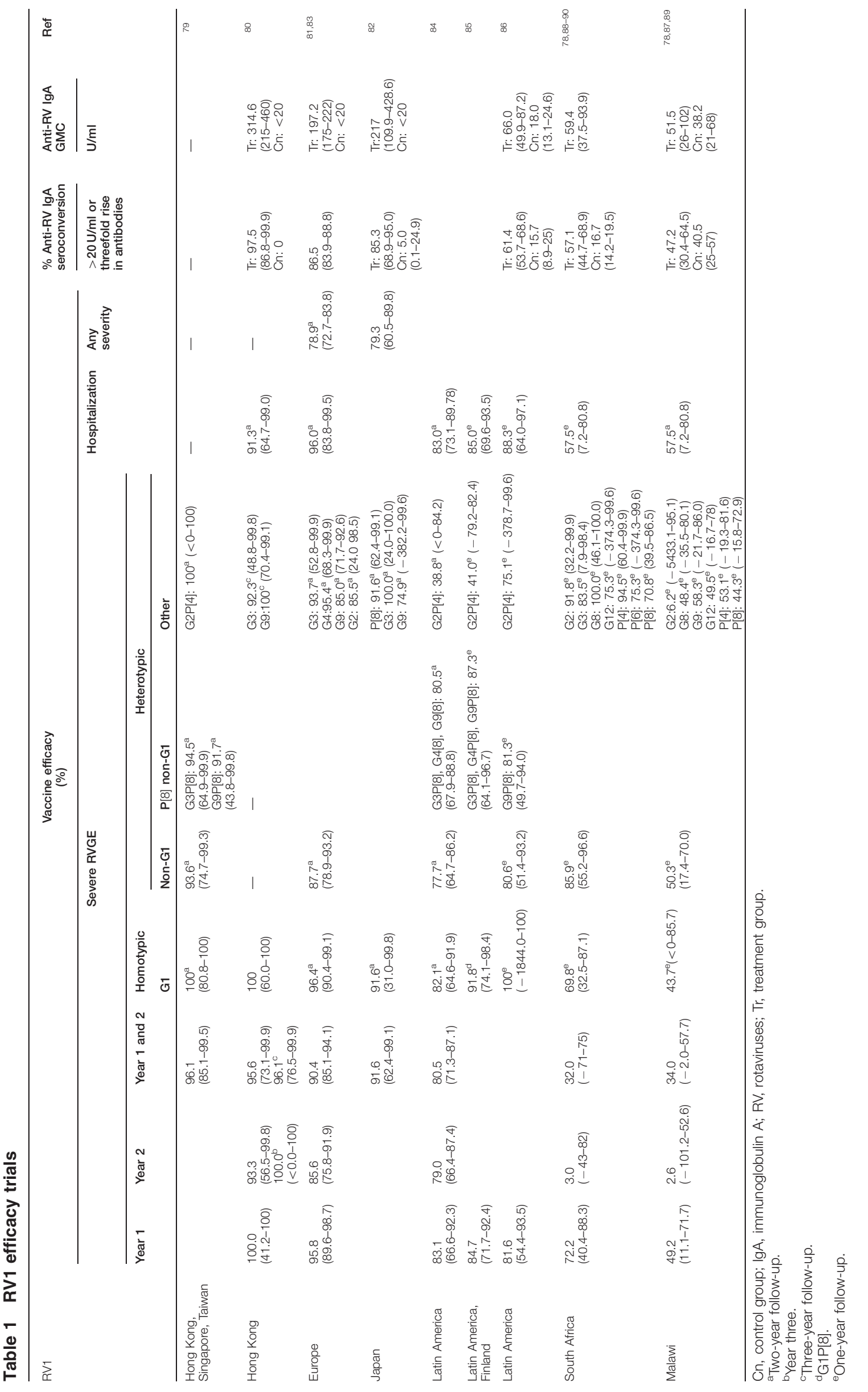




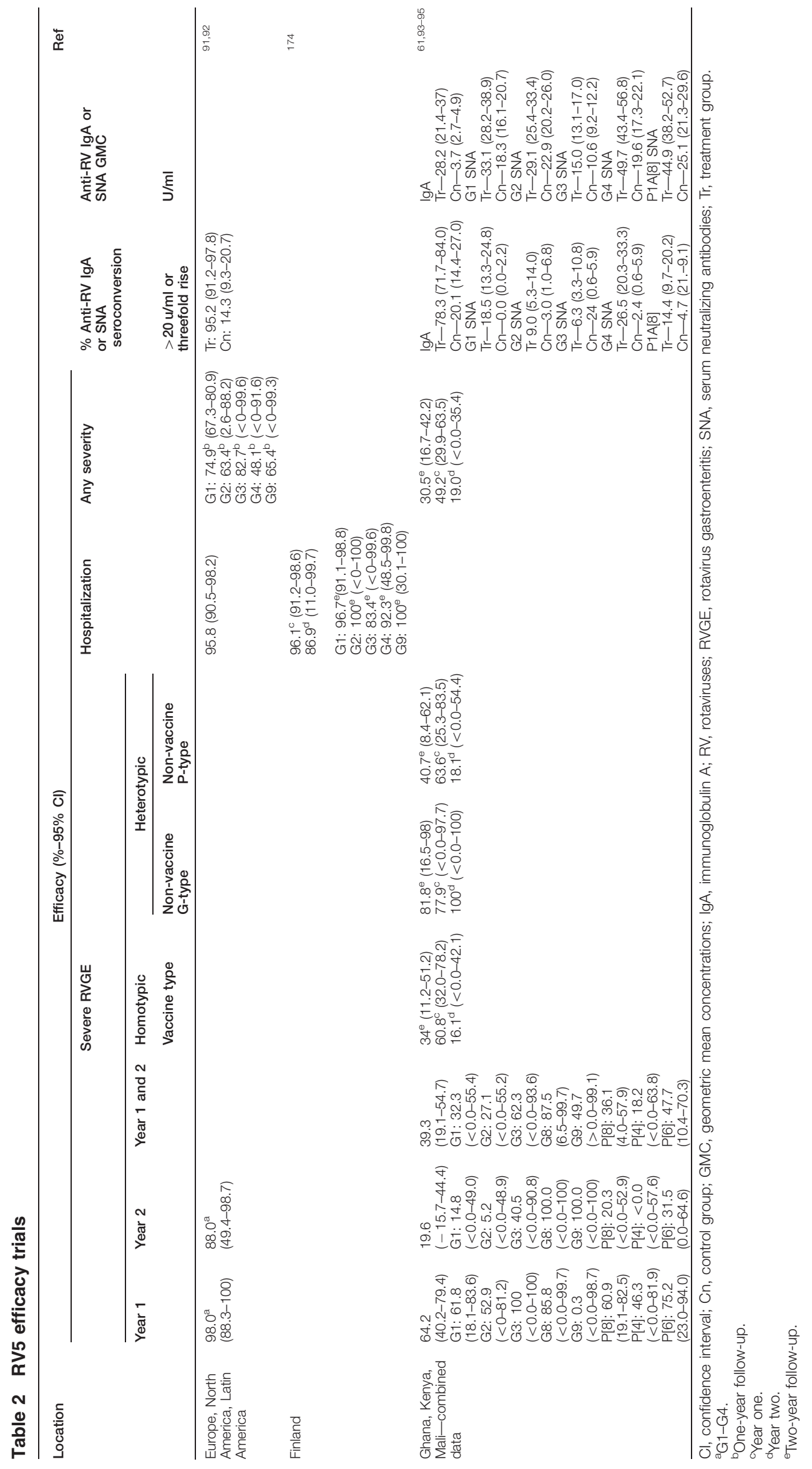




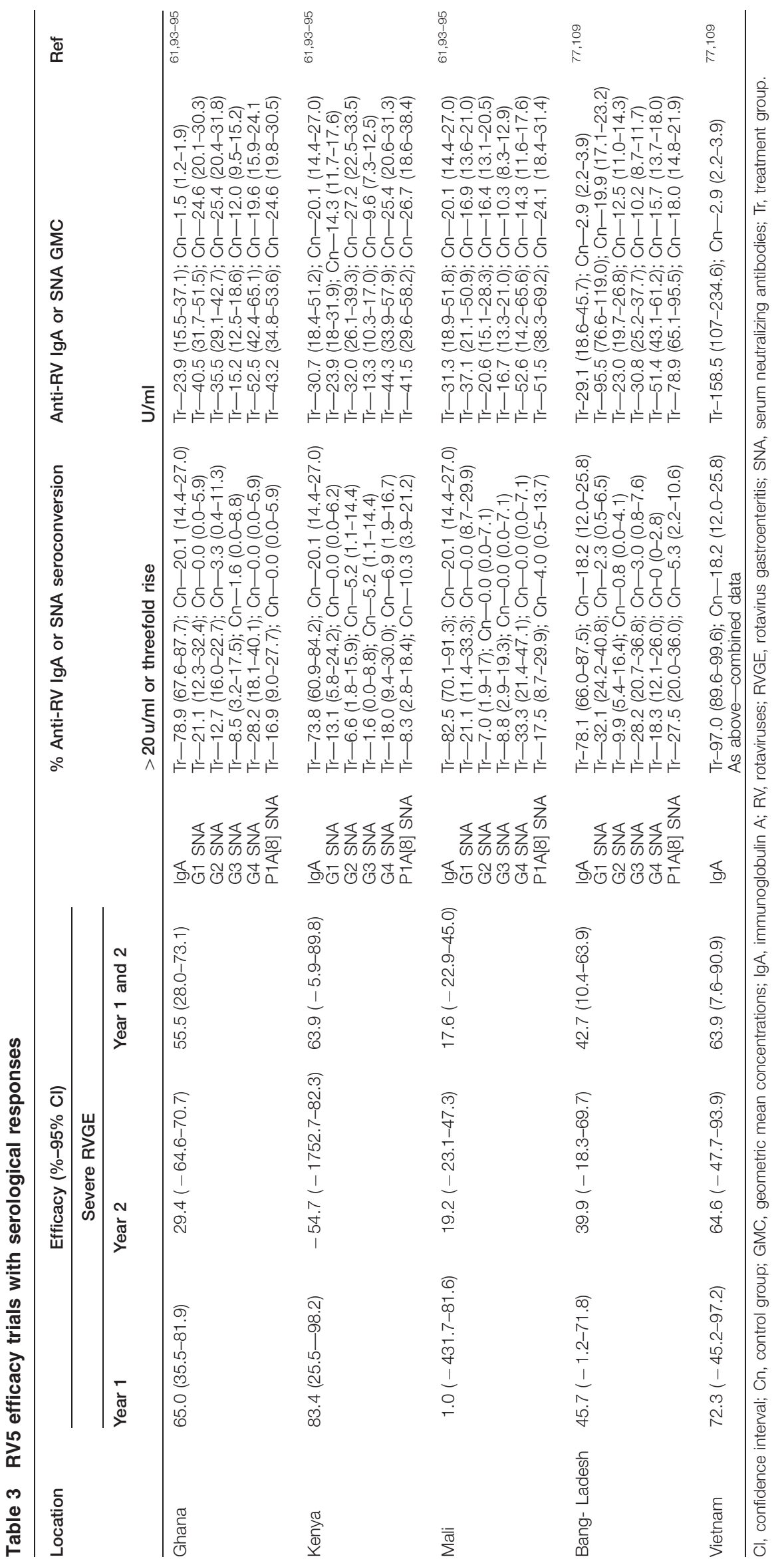




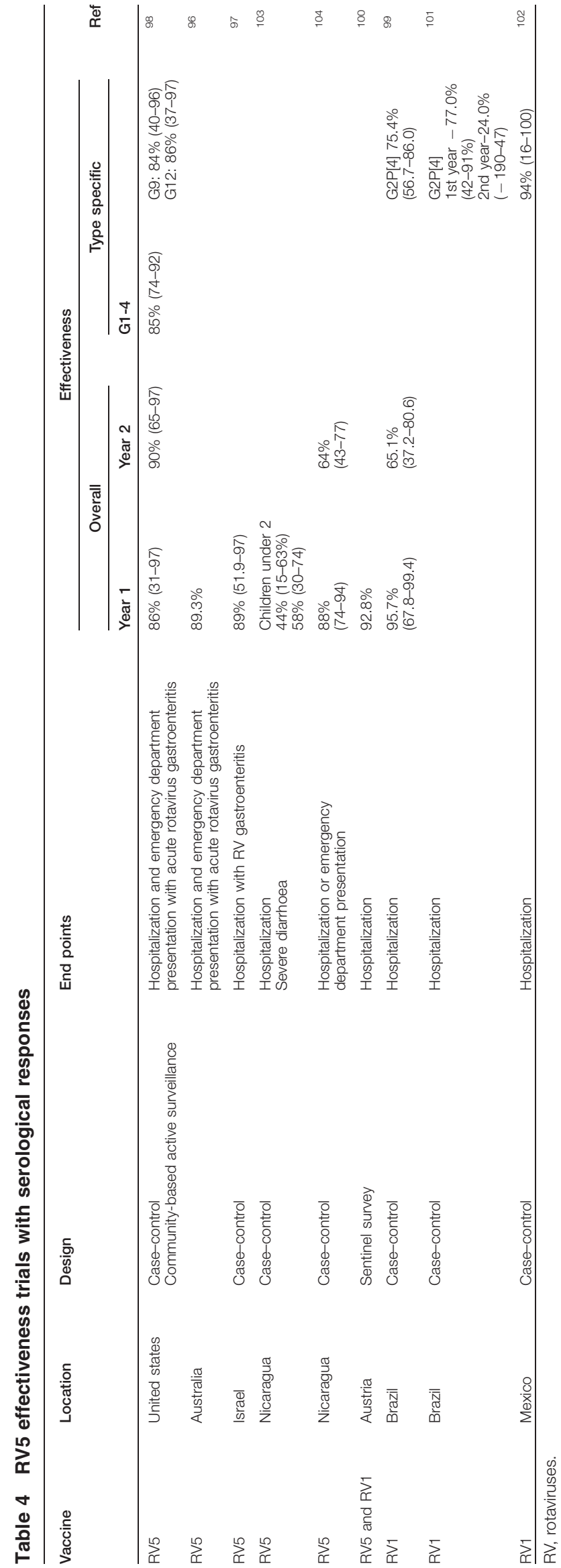

introduction, and in Austria following the introduction of a combination of RV1 and RV5, reported effectiveness figures of over $90 \%$ in year $1 .{ }^{99,100}$ In Mexico, RV1 was demonstrated to be greater than $94 \%$ effective against hospitalization up to 2 years of age with an emerging heterotypic G9P[4] strain, whereas the same vaccine was $77 \%$ effective up to 1 year of age against a G2P [4] strain in Brazil. ${ }^{101,102}$ Finally, in Nicaragua, the lowest income country from which effectiveness data are currently available, figures of between 46 and $76 \%$ effectiveness have been reported against hospitalization or emergency department presentation. ${ }^{103,104}$

Thus, in summary, high levels of vaccine efficacy have been reported for both RV1 and RV5 in high-income settings and such protection is well maintained until 2 years of age. Although homotypic protection may predominate, high levels of heterotypic protection are also induced by both vaccines. In contrast, lower and more variable levels of protection are generated in low-income settings in sub-Saharan Africa and Asia, and these findings are not explained solely by strain variation in these environments. In fact, in those resource-poor setting examined so far, heterotypic protection may predominate (perhaps generated through recurrent exposure). Moreover, the duration of protection appears to be reduced in these environments, with striking reductions in efficacy being reported in year 2, particularly in sub-Saharan Africa. Further effectiveness data from low-income countries are critically needed before the implications of the limited efficacy reported in these setting can be reliable quantified.

\section{CORRELATES OF HOMOTYPIC AND HETEROTYPIC VACCINE-INDUCED PROTECTION}

Research aimed at understanding the variable levels of protection conferred by the two licensed RV vaccines in different settings is currently hindered by the lack of an established correlate of vaccine-induced protection. ${ }^{105}$ Such an absence is also likely to impair the development of the next generation of RV vaccines by necessitating large-scale and time-consuming efficacy studies in relevant resource-limited settings. ${ }^{105}$ Although variable, the level of heterotypic protection induced by the vaccines indicates that type-specific antibodies directed against neutralizing VP7 or VP4 epitopes are not solely responsible for their protective effect. ${ }^{42}$ Indeed, the comparable efficacy of RV1 and RV5 reinforces this conclusion and neutralizing antibody titres induced by RV5 consistently underestimate the type-specific protection the vaccine confers. ${ }^{77,91,93,106}$ Furthermore, limited strain diversity worldwide suggests that neutralizing antibodies are not driving the long-term selective pressure, which would favor antigenic drift or the emergence of novel genotypes. ${ }^{20}$ Nonetheless, a cyclical pattern of individual genotypes has been reported, which would be consistent with some build-up of homotypic immunity against a predominant strain within the population. ${ }^{107}$ However, even in this context, the introduction of novel strains, expressing distinct $G$ and $P$ antigens, does not appear to be associated with unduly severe disease, further supporting the 


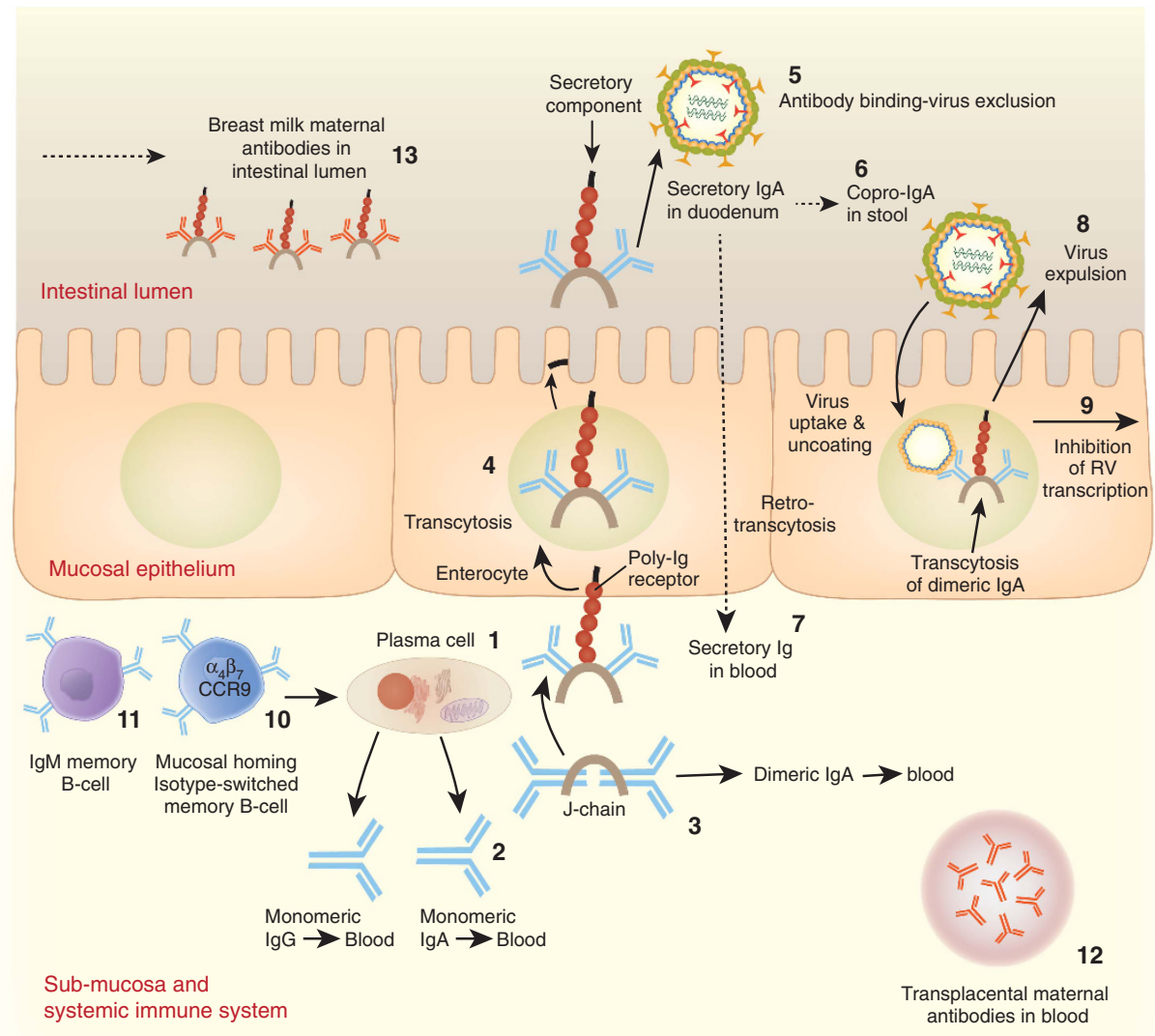

Figure 3 Proposed mechanisms of antibody-mediated RV immunity. (1) Plasma cells present in the mucosa (e.g., the lamina propria in the intestine) include populations (2) secreting monomeric IgA and IgG which can be measured in the blood stream as well as a high proportion (3) secreting dimeric IgA (linked by the J-chain), which can similarly be measured in the blood. (4) Dimeric IgA (and also pentameric IgM) interact with the poly-immunoglobulin receptor (plgR) on the basolateral surface of the enterocyte, resulting in endosomal uptake and transcytosis to the apical surface. (5) The dimeric IgA is released into the intestinal lumen following proteolytic cleavage, while remaining bound to the secretory component of the plgR-generating secretory lgA in the intestinal lumen. This binds to RV resulting in virus exclusion from the mucosa thus preventing infection. (6) Copro-lgA can be detected in the stool and correlates with the levels in the duodenum providing a marker of immunity at the site of infection. (7) Secretory immunoglobulin can also be measured in serum following presumed retro-transcytosis across the mucosal epithelium and may more accurately reflect intestinal immunity. (8) During transcytosis, non-neutralizing, anti-VP6 antibodies may bind RV following uncoating and exposure of VP6 as part of viral replication, which is thought to result in viral expulsion. (9) Anti-VP6 antibodies also inhibit viral transcription. (10) Isotype-switched memory B cells with a mucosal-homing phenotype can be detected following RV vaccination and show some correlation with immunity. (11) IgM memory B cells predominate in the RV-specific memory B-cells pool in humans, although their role in human immunity has not been determined. (12) RV-IgG is also transferred vertically-mother to infant across the placenta, and may have a role in immunity in neonates. (13) RV-specific secretory antibodies are transferred in breast milk, most notably in colostrum, although these antibodies cannot be detected in the serum in the same way as the infant's own secretory antibody.

existence of cross-reactive protective mechanisms beyond those conferred by type-specific neutralizing antibodies. ${ }^{20,108}$

A number of the proposed mechanisms of protection against $\mathrm{RV}$ infection in humans are outlined in Figure 3. In many of the efficacy studies reported to date, the induction of RV-specific serum IgA has been used as a marker of vaccine response $e^{61,77,78,80-82,85-87,91,93,94,109,110}$ and type-specific neutralizing antibody titres have been reported in addition in some trials ${ }^{61,77,91,93,109,111}$ (Tables 1-3). Seroresponse rates, either the percentage of infants undergoing seroconversion ('negative' to 'positive') or the percentage of infants with a given, generally at least threefold rise in titre are reported to indicate a response to a given vaccine. A systematic review examining the value of anti-RV serum IgA as a correlate of RV vaccine efficacy demonstrated that both the level and maintenance of protection following $\mathrm{RV}$ vaccination was lower in those setting from which lower IgA seroresponse rates were reported and, consistent with this, that under-five mortality rates, in countries of different WHO mortality strata, inversely correlated with IgA titres. ${ }^{22}$ An additional study has recently demonstrated a correlation between RVspecific immunoglobulin bound to the secretory fragment (both IgA and IgM) and protection against RV disease, thus providing a more direct link between mucosal immunity and disease. ${ }^{112}$ Although such figures serve to define the proportion of a given population in which a response to a vaccine or vaccine series is observed, the lack of discrete serological and outcome data from individual vaccine recipients prevents the definition 
of correlates predictive of protection in the individual. ${ }^{22}$ Furthermore, the measurement of total anti-RV IgA titres does not provide any information regarding the RV protein targets of heterotypic protection. Such information would be valuable in directing future vaccine development.

The mechanisms and the antigenic targets underlying heterotypic protection induced by the vaccines, through which more effective correlates might be derived, are currently not well understood. The presence of antibodies against nonneutralizing cross-reactive VP4 and VP7 epitopes or against common RV antigens including VP6 has been suggested. T-cell responses to conserved protein epitopes is another possibility. ${ }^{42}$ In humans, high levels of VP6-specific antibodies have been demonstrated following both natural RV infection and vaccination. ${ }^{113,114}$ Indeed, conserved anti-VP6 specific antibodies are the most common antibodies produced by $\mathrm{RV}$-specific $\mathrm{B}$ cells, including those expressing mucosal homing receptors. ${ }^{115-117}$ Recently, a sensitive method in which recombinant VP6 has been used to study the antibody response induced by human RV infection has been described. ${ }^{118}$ In mouse models, non-neutralizing anti-VP6 polymeric IgA antibodies have demonstrated antiviral and partially protective effects. These appear to be mediated through the capacity of the antibodies, acting intra-cellularly, to block the passage of RV across the mucosal cell layer and subsequently to 'expulse' the virus into the gut. ${ }^{20,25}$ Consistent with this, the effect of the VP6 antibodies is dependent on their production and subsequent transcytosis across the basolateral surface of the gut mucosa and is not replicated when the antibodies are delivered directly into the lumen. ${ }^{20,25}$ Antibodies against VP6 have also been shown to inhibit intracellular viral transcription, which likely also explains their antiviral effect. ${ }^{119,120}$ Human anti-VP6 IgA neutralizes transcriptionally active RV intracellularly and the binding site for these conserved antibodies has recently been defined. ${ }^{121}$ In contrast to these findings, anti-VP6 antibodies are not protective in piglets despite their local production in the gut, and although present, their functional role in heterotypic immunity in humans should now be determined. ${ }^{26}$ Similarly, antibodies against the viral enterotoxin NSP4 have been shown to confer protection in mice, even following oral administration, but do not provide protection in piglets. ${ }^{122,123}$ Finally, antibodies that block the interaction between the virus particle and HBGA, thus blocking initial viral attachment in the intestinal mucosa, have been shown to confer protection from norovirus infection ${ }^{124}$ and should be explored in the context of identifying correlates of protection from RV infection.

Beyond these serological measures, the effect of RV infection on the innate immune system and on both the T-cell and B-cell compartments are increasingly well described, although these largely mechanistic studies have yet to determine the influence of these responses on protection in humans. In mice, RV replication is inhibited by type III and to a lesser degree type I interferons. ${ }^{125}$ Reflecting this, the virus has mechanisms, demonstrated in human intestinal cell lines and mediated through transcription factor degradation by NSP-1, to inhibit interferon secretion. ${ }^{126}$ Nonetheless, the expression of type I interferons as well as of pro-inflammatory cytokines (TNF- $\alpha$, IL-1 $\beta$, IL-6) in humans has been shown to be upregulated in cells isolated from individual infected with RV compared with healthy controls. ${ }^{127}$

The virus has also been shown to drive the secretion of TGF- $\beta$ by a human intestinal cell line in vitro, resulting in an inhibition of Th1 responses by dendritic cells. ${ }^{128,129}$ In addition, the transcription of genes, associated with T-cell development and activation, is lower in children with acute RV infection compared with healthy controls. ${ }^{127}$ In fact, the virus does not appear to induce efficient CD4 + or CD8 + T-cell responses in humans, and any responses induced in children are generally at a lower frequency than those induced in adults. ${ }^{127,130-132}$ Nonetheless, RV-specific CD4 $+\mathrm{T}$ cells expressing the mucosal homing receptors $\alpha_{4} \beta_{7}$ and CCR9 have been detected using $\mathrm{RV}$-specific tetramer staining following $\mathrm{RV}$ vaccination in children. ${ }^{133}$ The transcription of genes associated with B-cell development and activation is increased in association with RV infection in childhood. ${ }^{127} \mathrm{RV}$ infects human intestinal memory $B$ cells in vitro more efficiently than those present in the blood stream. ${ }^{134}$ Furthermore, the virus inhibits the differentiation of memory B cells into plasma cells and also reduces the production of IL- 6 and IL-8, promoting its own replication. ${ }^{134}$ A weak correlation between the number of RV-specific isotypeswitched memory B cells, with a mucosal homing phenotype $\left(\alpha_{4} \beta_{7}^{+}\right.$CCR9 $\left.^{+}\right)$and protection from disease, has been reported. ${ }^{135}$ Recently, it has also been shown that IgM memory B cells predominate within the RV specific B-cell pool in humans and that the adoptive transfer of this population into mice results in lower levels of viraemia as well as in the induction of both IgM and IgG responses on RV challenge. ${ }^{136}$ Thus, building in part on findings from animal models, important data have been accumulated regarding the interaction between RV and the human immune system, including at the mucosal level. The correlation of such findings with serological responses and ultimately with protection in humans represent important next steps of research.

\section{DETERMINANTS OF VACCINE-INDUCED PROTECTION}

The variable levels of protection reported in different settings are not unique to the RV vaccines as both the oral polio and the oral cholera vaccines also show reduced efficacy in resourcelimited environments. ${ }^{137}$ Although the reasons for these observations are likely to be multi-factorial and to include environmental, viral and host factors, the identification of key determinants should allow strategies to be designed, which, even if resulting in only modest improvements in effectiveness individually, could nonetheless have significant public health impact overall. A number of interrelated factors have been considered and are illustrated in Figure $4 .{ }^{137}$

Environmental enteropathy is a sub-clinical condition, which is characterized by histological as well as function abnormalities in the small intestine and which appears to be almost ubiquitous in children living in resource-poor settings. ${ }^{138}$ The condition is thought to reflect chronic exposure to fecal pathogens in the environment due to poor sanitation, 


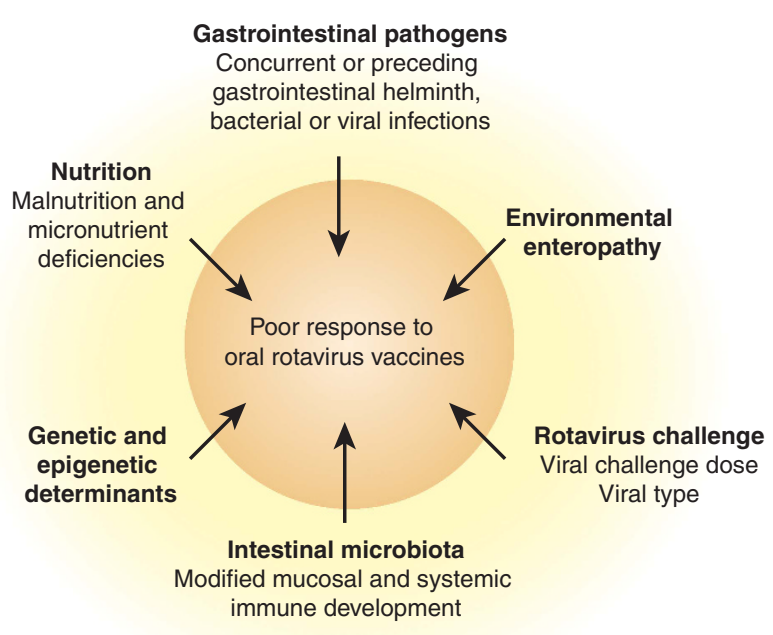

Figure 4 Possible modifiers of rotaviruses protection in resource-poor settings.

resulting in chronic intestinal inflammation. ${ }^{139}$ The inflammation is likely to be mediated through the stimulation of innate pattern-recognition receptors by conserved bacterial components; for example lipopolysaccharide from Gramnegative organisms. This is reflected initially in an increase in the release of pro-inflammatory cytokines and by inflammatory cell infiltration of the gut and subsequently enteric T-cell stimulation and a cell-mediated enteropathy. ${ }^{138,140,141}$ Such pathology leads to increases in intestinal permeability and bacterial translocation along with malabsorption and growth faltering. Reflecting this, in Gambian infants, increases in lipopolysaccharide-specific antibodies (EndoCab), associated with gut translocation of Gram-negative bacteria, have been used to study the condition in parallel with the lactosemannitol urinary excretion test, the most widely accepted surrogate marker of the condition. ${ }^{142,143}$ Furthermore, a several fold higher number of activated lymphocytes in the gut of Gambian infants has been reported compared with UK controls associated with a progressive switch away from a regulatory cytokine environment, preventing pathological responses to commensal species, towards a pro-inflammatory one. ${ }^{138}$ Although the importance of environmental enteropathy in undernutrition and poor growth is increasingly well described and the immunological effects of the condition are recognized, its role in the reduced efficacy of RV and other oral vaccines in a low-income setting remains speculative. Nonetheless, the histological changes associated with environmental enteropathy occur within the first few months of life, and therefore, it is reasonable to imagine that the condition could alter the response to RV vaccination even at this early age. ${ }^{144}$ Consequently, the need for research in this area is urgent, given some potential for intervention. ${ }^{137,141}$

Inextricably linked with environmental enteropathy are differences in the colonizing microbiota of the gut when infants in high- and middle-income countries are compared with those born in low-income settings. The microbiota of children living in low-income countries has been shown to be distinct in its composition, as well as being more diverse and more variable over time, when compared with the microbiota of children living in high-income countries. ${ }^{145-147}$ Mode of delivery and infant-feeding practices have also been shown to independently modify microbial composition in infancy. ${ }^{148}$ Although current data are largely derived from animal models, the influence of the intestinal microbiota on the immune system is increasingly well described and must now be translated to humans if public health impact is to be felt. ${ }^{149,150}$ In murine models, the nature of the colonizing species influences the quality of innate immune responses as well as the development of lymphoid structures and lymphocyte subsets, including Th17 and regulatory T cells, both of which have important roles in mucosal immune responses. ${ }^{151,152}$ These effects are not limited to the mucosal compartment, but also extend to the systemic immune system. ${ }^{153-156}$ Moreover, germ-free mice have significantly reduced the levels of IgA-producing cells in the intestine, ${ }^{157}$ and a number of different mechanisms, acting predominately through the triggering pattern recognition receptors, appear to influence the induction of intestinal IgA production by commensal organisms. ${ }^{158-161}$ In humans, intestinal colonization with Escherichia coli or bifidobacteria at 4 weeks of age has been associated with significant differences in memory B-cell numbers when the infants reached 18 month $^{162}$ Given such findings, it is easy to imagine that the documented differences in colonizing species in early life between high- and low-income settings ${ }^{163}$ could significantly influence the subsequent immune responses generated by oral vaccination by modifying both innate and adaptive immune development and function. One would hypothesize that such effects would be magnified in infants suffering with significant pro-inflammatory enteric infections before the receipt of their first RV vaccine, and in those in whom enteric co-infections were present at the time of vaccine administration. In fact, treatment of the intestinal helminth, Ascaris lumbricoides, with albendazole prior to the administration of an oral cholera vaccine has already been shown to enhance the seroresponse rates to this vaccine. ${ }^{164}$

A number of other factors have also been proposed to influence the protective efficacy of RV vaccines in resourcepoor settings and require additional exploration. ${ }^{137}$ Independently of environmental enteropathy, nutritional deficiencies including zinc, vitamin $\mathrm{A}$, and vitamin $\mathrm{D}$ have documented effects on the immune system, which may influence the protection that these vaccines induce. In addition, although maternal antibodies may offer protection from disease, both transplacental and breast milk antibodies may also compromise the effectiveness of the vaccines given in early life. ${ }^{70}$

\section{FUTURE DIRECTIONS}

Defining the correlates of protection against RV disease induced by vaccination will allow the impact of the current vaccine roll-out to be better predicted on the basis of immunogenicity rather than large-scale effectiveness studies and will also provide a benchmark for the testing and licensure 
of the next generation of RV vaccines. Such correlates are needed with increasing urgency as the size of efficacy trials, undertaken in the context of already partially effective vaccines, will become increasingly prohibitive.

The nesting of suitably powered prospective case-control studies, designed to define immunological correlates, within forthcoming vaccine effectiveness trials in resource-limited settings should be viewed as a key opportunity with this regard. Planned effectiveness trials will systematically collect clinical and RV type-specific virological outcome data on vaccinated infants. The additional measurement of candidate serological correlates and RV-specific cellular parameters from the same infants within a defined, generally 4-6 week time window following vaccination, provides an opportunity to determine protective thresholds. On the basis of existing data, and also considering the ease of assay standardization and future applicability, the definition of a serological correlate should be prioritized, whereas $\mathrm{RV}$-specific cellular response should be examined in order to gain mechanistic insight. The definition of an absolute or relative threshold of RV-IgA-associated individual protection from RV-associated MSD (or other disease end point) would represent an important step. ${ }^{165,166}$ In addition, the concurrent measurement of RV-SIg and coproIgA may establish either as more sensitive markers. ${ }^{53,58}$ The application of novel assays to quantify anti-VP6, anti-NSP4, and HBGA-blocking antibodies would further provide an opportunity to understand their relative role in heterotypic protection when examined in the context of RV type-specific disease outcome data. ${ }^{18,167}$

RV-specific B-cell and T-cell responses can now be measured by flow-cytometry using fluorescently labels virus-likeparticles and RV-specific $\mathrm{CD} 4+$ tetramer staining, respectively. ${ }^{133,168}$ Human CD8 epitopes from VP7 have also been defined facilitating the identification of $\mathrm{CD} 8$ responses on the basis of MHC class I multimer staining. ${ }^{169}$ The measurement of these adaptive cellular readouts alongside serological and clinical outcome data would provide a key opportunity to further understand the importance of these populations in human RV immunity.

Finally, understanding the dominant factors responsible for the reduced efficacy of $\mathrm{RV}$ vaccines in resource-limited settings will be an important step towards improving vaccine efficacy in the future. With this regard, the application of increasingly powerful systems vaccinology approaches to dissecting the complex interplay of factors has the potential to provide unique new insights. ${ }^{170,171}$ The identification of the transcriptomic (and other '-omic') signatures, including the dominant innate and adaptive signalling pathways, and pathways involved in other metabolic processes activated over a time-course following vaccination, should provide a more global view of the response induced by $\mathrm{RV}$ vaccines than that available using conventional techniques. Comparison of such signatures in serological responders and non-responders as well as in infants in different socio-economic settings will be hypothesis generating and should direct further confirmatory studies and interventional trials towards areas of interest. The examination of the intestinal microbiome alongside conventional microscopy- and culture-based techniques for bacterial and parasite identification will provide additional information. ${ }^{163}$ It should be noted that the techniques to effectively interrogate the large combined data sets that both the above approaches generate are rapidly progressing but are still in their relative infancy. ${ }^{172}$

In conclusion, huge strides have been made in the fields of rotavirus immunology and vaccinology culminating in the current global roll out of two RV vaccines. The vaccines are highly effective in resource-rich settings and will offer a level of protection in resource-limited settings which is yet to be determined in effectiveness trials. In addition, the next generation of RV vaccines, including parenterally administered, non-replicating rotavirus vaccines, are in various stages of pre-clinical and clinical development. ${ }^{173}$ Nonetheless, key questions must be addressed by mucosal immunologists and vaccinologists, if the future impact of vaccination on RVassociated morbidity and mortality is to be maximized.

\section{DISCLOSURE}

The authors declare no conflict of interest.

c 2015 Society for Mucosal Immunology

\section{REFERENCES}

1. Parashar, U.D. et al. Global mortality associated with rotavirus disease among children in 2004. J. Infect. Dis. 200 (Suppl 1), S9-S15 (2009).

2. Parashar, U.D., Bresee, J.S. \& Glass, R.I. The global burden of diarrhoeal disease in children. Bull. World Health Organ. 81, 236 (2003).

3. Parashar, U.D. et al. Global illness and deaths caused by rotavirus disease in children. Emerg. Infect. Dis. 9, 565-572 (2003).

4. Bryce, J. et al. WHO estimates of the causes of death in children. Lancet 365, 1147-1152 (2005).

5. Tate, J.E. et al. 2008 estimate of worldwide rotavirus-associated mortality in children younger than 5 years before the introduction of universal rotavirus vaccination programmes: a systematic review and metaanalysis. Lancet Infect. Dis. 12, 136-141 (2012).

6. Estes, M.K. \& Kapikan, A.Z. Rotaviruses, in Fields Virology (Knipe, D.M. \& Howley, P.M., eds) 1917-1974 (Wolters Kluwer Health/Lippincott Williams and Wilkins, Philadelphia, 2007).

7. Settembre, E.C. et al. Atomic model of an infectious rotavirus particle. Embo. J. 30, 408-416 (2011).

8. Liu, Y. et al. Rotavirus VP8*: phylogeny, host range, and interaction with histo-blood group antigens. J. Virol. 86, 9899-9910 (2012).

9. Ramani, S. et al. The VP8* Domain of Neonatal Rotavirus Strain G10P[11] Binds to Type II Precursor Glycans. J. Virol. 87, 7255-7264 (2013).

10. Hu, L. et al. Cell attachment protein VP8* of a human rotavirus specifically interacts with A-type histo-blood group antigen. Nature 485, 256-259 (2012).

11. Imbert-Marcille, B.M. et al. A FUT2 gene common polymorphism determines resistance to Rotavirus A of the P[8] genotype. J. Infect. Dis. 209, 1227-1230 (2013).

12. Matthijnssens, J. et al. VP6-sequence-based cutoff values as a criterion for rotavirus species demarcation. Arch. Virol. 157, 11771182 (2012).

13. Kindler, E. et al. Analysis of rotavirus species diversity and evolution including the newly determined full-length genome sequences of rotavirus F and G. Infect. Genet. Evol. 14, 58-67 (2013).

14. Santos, N. \& Hoshino, Y. Global distribution of rotavirus serotypes/genotypes and its implication for the development and implementation of an effective rotavirus vaccine. Rev. Med. Virol. 15, 29-56 (2005). 
15. Gentsch, J.R. et al. Serotype diversity and reassortment between human and animal rotavirus strains: implications for rotavirus vaccine programs. J. Infect. Dis. 192 (Suppl 1), S146-S159 (2005).

16. Todd, S. et al. Rotavirus strain types circulating in Africa: review of studies published during 1997-2006. J. Infect. Dis 202 (Suppl), S34-S42 (2010).

17. Matthijnssens, J. et al. Uniformity of rotavirus strain nomenclature proposed by the Rotavirus Classification Working Group (RCWG). Arch. Virol. 156, 1397-1413 (2011).

18. Matthijnssens, J. et al. Full genome-based classification of rotaviruses reveals a common origin between human Wa-Like and porcine rotavirus strains and human DS-1-like and bovine rotavirus strains. J. Virol. 82, 3204-3219 (2008)

19. Matthijnssens, J. \& Van Ranst, M. Genotype constellation and evolution of group A rotaviruses infecting humans. Curr. Opin. Virol. 2, 426-433 (2012).

20. Franco, M.A., Angel, J. \& Greenberg, H.B. Immunity and correlates of protection for rotavirus vaccines. Vaccine 24, 2718-2731 (2006).

21. Desselberger, U. \& Huppertz, H.I. Immune responses to rotavirus infection and vaccination and associated correlates of protection. J. Infect. Dis. 203, 188-195 (2011).

22. Patel, M. et al. A systematic review of anti-rotavirus serum IgA antibody titer as a potential correlate of rotavirus vaccine efficacy. J. Infect. Dis $\mathbf{2 0 8}$ 284-294 (2013).

23. Burns, J.W. et al. Analyses of homologous rotavirus infection in the mouse model. Virology 207, 143-153 (1995).

24. Franco, M.A. \& Greenberg, H.B. Immunity to rotavirus infection in mice. J. Infect. Dis. 179 (Suppl 3), S466-S469 (1999).

25. Burns, J.W. et al. Protective effect of rotavirus VP6-specific IgA monoclonal antibodies that lack neutralizing activity. Science 272, 104-107 (1996).

26. Yuan, L. et al. Intranasal administration of 2/6-rotavirus-like particles with mutant Escherichia coli heat-labile toxin (LT-R192G) induces antibodysecreting cell responses but not protective immunity in gnotobiotic pigs. J. Virol. 74, 8843-8853 (2000).

27. Bernstein, D.I. et al. Protection from rotavirus reinfection: 2-year prospective study. J. Infect. Dis. 164, 277-283 (1991).

28. Velazquez, F.R. et al. Rotavirus infections in infants as protection against subsequent infections. N. Engl. J. Med. 335, 1022-1028 (1996).

29. White, L.J. et al. Rotavirus within day care centres in Oxfordshire, UK: characterization of partial immunity. J. R. Soc. Interface. 5, 1481-1490 (2008).

30. Fischer, T.K. et al. Protective immunity after natural rotavirus infection: a community cohort study of newborn children in Guinea-Bissau, west Africa. J. Infect. Dis. 186, 593-597 (2002).

31. Huang, P. et al. Spike protein VP8* of human rotavirus recognizes histoblood group antigens in a type-specific manner. J. Virol. 86, 4833-4843 (2012).

32. Liu, Y. et al. Poly-LacNAc as an age-specific ligand for rotavirus $P[11]$ in neonates and infants. PLoS One 8, e78113 (2013).

33. Ruuska, T. \& Vesikari, T. Rotavirus disease in Finnish children: use of numerical scores for clinical severity of diarrhoeal episodes. Scand. J. Infect. Dis. 22, 259-267 (1990).

34. Gladstone, B.P. et al. Protective effect of natural rotavirus infection in an Indian birth cohort. N. Engl. J. Med. 365, 337-346 (2011).

35. Bishop, R.F. et al. Clinical immunity after neonatal rotavirus infection. A prospective longitudinal study in young children. N. Engl. J. Med. 309, 72-76 (1983)

36. Ramani, S. et al. Rotavirus infection in the neonatal nurseries of a tertiary care hospital in India. Pediatr. Infect. Dis. J. 27, 719-723 (2008).

37. Das, M. et al. Both surface proteins (VP4 and VP7) of an asymptomatic neonatal rotavirus strain (I321) have high levels of sequence identity with the homologous proteins of a serotype 10 bovine rotavirus. Virology 194 374-379 (1993).

38. Banerjee, I. et al. Neonatal infection with G10P[11] rotavirus did not confer protection against subsequent rotavirus infection in a community cohort in Vellore, South India. J. Infect. Dis. 195, 625-632 (2007).

39. Vethanayagam, R.R. et al. Possible role of neonatal infection with the asymptomatic reassortant rotavirus (RV) strain 1321 in the decrease in hospital admissions for RV diarrhea, Bangalore, India, 1988-1999. J. Infect. Dis. 189, 2282-2289 (2004).
40. Ramani, S. et al. Whole genome characterization of reassortant G1OP[11] strain (N155) from a neonate with symptomatic rotavirus infection: identification of genes of human and animal rotavirus origin. J. Clin. Virol. 45, 237-244 (2009)

41. Angel, J., Franco, M.A. \& Greenberg, H.B. Rotavirus vaccines: recent developments and future considerations. Nat. Rev. Microbiol. 5, 529-539 (2007).

42. Angel, J., Franco, M.A. \& Greenberg, H.B. Rotavirus immune responses and correlates of protection. Curr. Opin. Virol. 2, 419-425 (2012).

43. Arias, C.F. et al. Neutralizing antibody immune response in children with primary and secondary rotavirus infections. Clin. Diagn. Lab. Immunol. 1, 89-94 (1994).

44. O'Ryan, M.L. et al. Acquisition of serum isotype-specific and G typespecific antirotavirus antibodies among children in day care centers. Pediatr. Infect. Dis. J. 13, 890-895 (1994).

45. Blutt, S.E. et al. Rotavirus antigenaemia and viraemia: a common event?. Lancet 362, 1445-1449 (2003).

46. Blutt, S.E. \& Conner, M.E. Rotavirus: to the gut and beyond!. Curr. Opin. Gastroenterol. 23, 39-43 (2007).

47. Blutt, S.E. et al. Rotavirus antigenemia in children is associated with viremia. PLoS Med 4, e121 (2007).

48. Chiba, S. et al. Protective effect of naturally acquired homotypic and heterotypic rotavirus antibodies. Lancet 2, 417-421 (1986).

49. Ward, R.L. et al. Evidence that protection against rotavirus diarrhea after natural infection is not dependent on serotype-specific neutralizing antibody. J. Infect. Dis. 166, 1251-1257 (1992).

50. Velazquez, F.R. et al. Serum antibody as a marker of protection against natural rotavirus infection and disease. J. Infect. Dis. 182, 1602-1609 (2000).

51. O'Ryan, M.L. et al. Anti-rotavirus G type-specific and isotype-specific antibodies in children with natural rotavirus infections. J. Infect. Dis. 169, 504-511 (1994)

52. Hjelt, K. et al. Protective effect of preexisting rotavirus-specific immunoglobulin A against naturally acquired rotavirus infection in children. J. Med. Virol. 21, 39-47 (1987)

53. Hjelt, K. et al. Intestinal and serum immune response to a naturally acquired rotavirus gastroenteritis in children. J. Pediatr. Gastroenterol. Nutr. 4, 60-66 (1985).

54. Hjelt, K. et al. Rotavirus antibodies in the mother and her breast-fed infant. J. Pediatr. Gastroenterol. Nutr. 4, 414-420 (1985).

55. Grimwood, K. et al. Comparison of serum and mucosal antibody responses following severe acute rotavirus gastroenteritis in young children. J. Clin. Microbiol. 26, 732-738 (1988).

56. Bernstein, D.I., Ziegler, J.M. \& Ward, R.L. Rotavirus fecal IgA antibody response in adults challenged with human rotavirus. J. Med. Virol. 20, 297-304 (1986)

57. Matson, D.O. et al. Fecal antibody responses to symptomatic and asymptomatic rotavirus infections. J. Infect. Dis. 167, 577-583 (1993).

58. Coulson, B.S. et al. Role of coproantibody in clinical protection of children during reinfection with rotavirus. J. Clin. Microbiol. 30, 1678-1684 (1992).

59. Haffejee, I.E. Neonatal rotavirus infections. Rev. Infect. Dis. 13, 957-962 (1991).

60. Jayashree, S. et al. Neonatal rotavirus infection and its relation to cord blood antibodies. Scand. J. Infect. Dis. 20, 249-253 (1988).

61. Armah, G.E. et al. Immunogenicity of the pentavalent rotavirus vaccine in African infants. Vaccine 30 (Suppl 1), A86-A93 (2012).

62. Ramachandran, M. et al. Lack of maternal antibodies to P serotypes may predispose neonates to infections with unusual rotavirus strains. Clin. Diagn. Lab. Immunol. 5, 527-530 (1998).

63. Jayashree, S. et al. Protection against neonatal rotavirus infection by breast milk antibodies and trypsin inhibitors. J. Med. Virol. 26, 333-338 (1988).

64. Santos, S.M. et al. Milk from Brazilian women presents secretory lgA antibodies and neutralizes rotavirus G9P[5]. J. Pediatr. (Rio J) 89, 510-513 (2013)

65. Tino De Franco, M. et al. Neutralizing activity and secretory IgA antibodies reactive with rotavirus SA-11 (serotype G3) in colostrum and milk from Brazilian women. Paediatr. Int. Child Health 33, 102-107 (2013).

66. Moon, S.S. et al. Differential profiles and inhibitory effect on rotavirus vaccines of nonantibody components in breast milk from mothers in 
developing and developed countries. Pediatr. Infect. Dis. J. 32, 863-870 (2013).

67. Chan, J. et al. Maternal antibodies to rotavirus: could they interfere with live rotavirus vaccines in developing countries?. Vaccine $29,1242-1247$ (2011).

68. Asensi, M.T., Martinez-Costa, C. \& Buesa, J. Anti-rotavirus antibodies in human milk: quantification and neutralizing activity. J. Pediatr. Gastroenterol. Nutr. 42, 560-567 (2006).

69. Brussow, H. et al. Rotavirus-inhibitory activity in serial milk samples from Mexican women and rotavirus infections in their children during their first year of life. J. Clin. Microbiol. 31, 593-597 (1993).

70. Moon, S.S. et al. Inhibitory effect of breast milk on infectivity of live oral rotavirus vaccines. Pediatr. Infect. Dis. J. 29, 919-923 (2010).

71. Clemens, J. et al. Breast-feeding and the risk of life-threatening rotavirus diarrhea: prevention or postponement?. Pediatrics 92, 680-685 (1993).

72. Babji, S. \& Kang, G. Rotavirus vaccination in developing countries. Curr. Opin. Virol. 2, 443-448 (2012).

73. Lopman, B.A. et al. Post-licensure experience with rotavirus vaccination in high and middle income countries; 2006 to 2011. Curr. Opin. Virol. 2, 434-442 (2012).

74. Rotavirus vaccines. WHO position paper-January 2013. Wkly. Epidemiol. Rec. 88, 49-64 (2013).

75. WHO. Rotavirus vaccines:an update. Wkly. Epidemiol. Rec. 84, 533-540 (2009).

76. Lopman, B.A. et al. Understanding reduced rotavirus vaccine efficacy in low socio-economic settings. PLoS O 7, e41720 (2012).

77. Zaman, K. et al. Efficacy of pentavalent rotavirus vaccine against severe rotavirus gastroenteritis in infants in developing countries in Asia: a randomised, double-blind, placebo-controlled trial. Lancet 376, 615-623 (2010).

78. Madhi, S.A. et al. Effect of human rotavirus vaccine on severe diarrhea in African infants. N. Engl. J. Med. 362, 289-298 (2010).

79. Phua, K.B. et al. Safety and efficacy of human rotavirus vaccine during the first 2 years of life in Asian infants: randomised, double-blind, controlled study. Vaccine 27, 5936-5941 (2009).

80. Lau, Y.L. et al. Efficacy, safety and immunogenicity of a human rotavirus vaccine (RIX4414) in Hong Kong children up to three years of age: a randomized, controlled trial. Vaccine 31, 2253-2259 (2013).

81. Vesikari, $\mathrm{T}$. et al. Efficacy of human rotavirus vaccine against rotavirus gastroenteritis during the first 2 years of life in European infants: randomised, double-blind controlled study. Lancet 370, 1757-1763 (2007).

82. Kawamura, N. et al. Efficacy, safety and immunogenicity of RIX4414 in Japanese infants during the first two years of life. Vaccine 29, 6335-6341 (2011).

83. GlaxoSmithKline. Clinical Studies Register Study ID 102247-036. [cited 2013 24/07/2013]; Available fromhttp://www.gsk-clinicalstudyregister.$\mathrm{com} /$.

84. Linhares, A.C. et al. Efficacy and safety of an oral live attenuated human rotavirus vaccine against rotavirus gastroenteritis during the first 2 years of life in Latin American infants: a randomised, double-blind, placebocontrolled phase III study. Lancet 371, 1181-1189 (2008).

85. Ruiz-Palacios, G.M. et al. Safety and efficacy of an attenuated vaccine against severe rotavirus gastroenteritis. N. Engl. J. Med. 354, 11-22 (2006).

86. Tregnaghi, M.W. et al. Human rotavirus vaccine is highly efficacious when coadministered with routine expanded program of immunization vaccines including oral poliovirus vaccine in Latin America. Pediatr. Infect. Dis. J. 30, e103-e108 (2011).

87. Cunliffe, N.A. et al. Efficacy of human rotavirus vaccine against severe gastroenteritis in Malawian children in the first two years of life: a randomized, double-blind, placebo controlled trial. Vaccine 30 (Suppl 1), A36-A43 (2012).

88. Madhi, S.A. et al. Efficacy and immunogenicity of two or three dose rotavirus-vaccine regimen in South African children over two consecutive rotavirus-seasons: a randomized, double-blind, placebo-controlled trial. Vaccine 30 (Suppl 1), A44-A51 (2012).

89. Steele, A.D. et al. Human rotavirus vaccine Rotarix provides protection against diverse circulating rotavirus strains in African infants: a randomized controlled trial. BMC. Infect. Dis. 12, 213 (2012).
90. Steele, A.D. et al. Comparison of 2 different regimens for reactogenicity, safety, and immunogenicity of the live attenuated oral rotavirus vaccine RIX4414 coadministered with oral polio vaccine in South African infants. J. Infect. Dis. 202 (Suppl), S93-100 (2010).

91. Vesikari, T. et al. Safety and efficacy of a pentavalent human-bovine (WC3) reassortant rotavirus vaccine. N. Engl. J. Med. 354, 23-33 (2006).

92. Vesikari, T. et al. Efficacy of a pentavalent rotavirus vaccine in reducing rotavirus-associated health care utilization across three regions (11 countries). Int. J. Infect. Dis. 2007)11 (Suppl 2), S29-S35.

93. Armah, G.E. et al. Efficacy of pentavalent rotavirus vaccine against severe rotavirus gastroenteritis in infants in developing countries in sub-Saharan Africa: a randomised, double-blind, placebo-controlled trial. Lancet $\mathbf{3 7 6}$, 606-614 (2010).

94. Sow, S.O. et al. Efficacy of the oral pentavalent rotavirus vaccine in Mali. Vaccine 30 (Suppl 1), A71-A78 (2012).

95. Tapia, M.D. et al. Secondary efficacy endpoints of the pentavalent rotavirus vaccine against gastroenteritis in sub-Saharan Africa. Vaccine 30 (Suppl 1), A79-A85 (2012).

96. Buttery, J.P. et al. Reduction in rotavirus-associated acute gastroenteritis following introduction of rotavirus vaccine into Australia's National Childhood vaccine schedule. Pediatr. Infect. Dis. J. 30 (1 Suppl), S25-S29 (2011)

97. Muhsen, $\mathrm{K}$. et al. Effectiveness of rotavirus vaccines for prevention of rotavirus gastroenteritis-associated hospitalizations in Israel: a casecontrol study. Hum. Vaccin 6, 450-454 (2010).

98. Staat, M.A. et al. Effectiveness of pentavalent rotavirus vaccine against severe disease. Pediatrics 128, e267-e275 (2011).

99. Justino, M.C. et al. Effectiveness of the monovalent G1P[8] human rotavirus vaccine against hospitalization for severe G2P[4] rotavirus gastroenteritis in Belem, Brazil. Pediatr. Infect. Dis. J. 30, 396-401 (2011).

100. Paulke-Korinek, M. et al. Universal mass vaccination against rotavirus gastroenteritis: impact on hospitalization rates in austrian children. Pediatr. Infect. Dis. J. 29, 319-323 (2010).

101. Correia, J.B. et al. Effectiveness of monovalent rotavirus vaccine (Rotarix) against severe diarrhea caused by serotypically unrelated G2P[4] strains in Brazil. J. Infect. Dis. 201, 363-369 (2010).

102. Yen, C. et al. Monovalent rotavirus vaccine provides protection against an emerging fully heterotypic G9P[4] rotavirus strain in Mexico. J. Infect. Dis. 204, 783-786 (2011)

103. Patel, M. et al. Association between pentavalent rotavirus vaccine and severe rotavirus diarrhea among children in Nicaragua. Jama 301, 2243-2251 (2009).

104. Mast, T.C. et al. Case-control study of the effectiveness of vaccination with pentavalent rotavirus vaccine in Nicaragua. Pediatr. Infect. Dis. J. 30, e209-e215 (2011).

105. Parashar, U. et al. Progress with rotavirus vaccines: summary of the Tenth International Rotavirus Symposium. Expert Rev. Vaccines 12, 113-117 (2013).

106. Ciarlet, M. et al. Concomitant use of the oral pentavalent human-bovine reassortant rotavirus vaccine and oral poliovirus vaccine. Pediatr. Infect. Dis. J. 27, 874-880 (2008).

107. Pitzer, V.E. et al. Modeling rotavirus strain dynamics in developed countries to understand the potential impact of vaccination on genotype distributions. Proc. Natl. Acad. Sci. USA 108, 19353-19358 (2011).

108. Clark, H.F. et al. Assessment of the epidemic potential of a new strain of rotavirus associated with the novel G9 serotype which caused an outbreak in the United States for the first time in the 1995-1996 season. J. Clin. Microbiol. 42, 1434-1438 (2004).

109. Shin, S. et al. Immunogenicity of the pentavalent rotavirus vaccine among infants in two developing countries in Asia, Bangladesh and Vietnam. Vaccine 30 (Suppl 1), A106-A113 (2012).

110. Narang, A. et al. Immunogenicity, reactogenicity and safety of human rotavirus vaccine (RIX4414) in Indian infants. Hum. Vaccin 5, 414-419 (2009).

111. Ward, R.L. et al. Serologic correlates of immunity in a tetravalent reassortant rotavirus vaccine trial. US Rotavirus Vaccine Efficacy Group. J. Infect. Dis. 176, 570-577 (1997).

112. Herrera, D. et al. Rotavirus specific plasma secretory immunoglobulin in children with acute gastroenteritis and children vaccinated with 
an attenuated human rotavirus vaccine. Hum. Vaccin Immunother. 9 , 2409-2417 (2013).

113. Svensson, L. et al. Immune response to rotavirus polypeptides after vaccination with heterologous rotavirus vaccines (RIT 4237, RRV-1). J. Gen. Virol. 68 (Pt 7), 1993-1999 (1987).

114. Svensson, L. et al. Serum antibody responses to individual viral polypeptides in human rotavirus infections. J. Gen. Virol. 68 (Pt 3), 643-651 (1987).

115. Weitkamp, J.H. et al. Infant and adult human B cell responses to rotavirus share common immunodominant variable gene repertoires. J. Immunol. 171, 4680-4688 (2003).

116. Weitkamp, J.H. et al. VH1-46 is the dominant immunoglobulin heavy chain gene segment in rotavirus-specific memory B cells expressing the intestinal homing receptor alpha4beta7. J. Immunol. 174, 3454-3460 (2005).

117. Weitkamp, J.H., Lafleur, B.J. \& Crowe, J.E. Jr. Rotavirus-specific CD5 + $B$ cells in young children exhibit a distinct antibody repertoire compared with CD5- B cells. Hum. Immunol. 67, 33-42 (2006).

118. Kavanagh, O. et al. A time-resolved immunoassay to measure serum antibodies to the rotavirus VP6 capsid protein. J. Virol. Methods. 189, 228-231 (2013).

119. Feng, N. et al. Inhibition of rotavirus replication by a non-neutralizing, rotavirus VP6-specific IgA mAb. J. Clin. Invest. 109, 1203-1213 (2002).

120. Thouvenin, E. et al. Antibody inhibition of the transcriptase activity of the rotavirus DLP: a structural view. J. Mol. Biol. 307, 161-172 (2001).

121. Aiyegbo, M.S. et al. Human rotavirus VP6-specific antibodies mediate intracellular neutralization by binding to a quaternary structure in the transcriptional pore. PLoS One 8, e61101 (2013).

122. Ball, J.M. et al. Age-dependent diarrhea induced by a rotaviral nonstructural glycoprotein. Science 272, 101-104 (1996).

123. Yuan, L. et al. Species-specific but not genotype-specific primary and secondary isotype-specific NSP4 antibody responses in gnotobiotic calves and piglets infected with homologous host bovine (NSP4[A]) or porcine (NSP4[B]) rotavirus. Virology 330, 92-104 (2004).

124. Reeck, A. et al. Serological correlate of protection against norovirusinduced gastroenteritis. J. Infect. Dis. 202, 1212-1218 (2010).

125. Pott, J. et al. IFN-lambda determines the intestinal epithelial antiviral host defense. Proc. Natl. Acad. Sci. USA 108, 7944-7949 (2011).

126. Arnold, M.M. et al. The battle between rotavirus and its host for control of the interferon signaling pathway. PLoS Pathog. 9, e1003064 (2013).

127. Wang, Y. et al. Rotavirus infection alters peripheral T-cell homeostasis in children with acute diarrhea. J. Virol. 81, 3904-3912 (2007).

128. Barreto, A. et al. Membrane vesicles released by intestinal epithelial cells infected with rotavirus inhibit T-cell function. Viral. Immunol. 23, 595-608 (2010).

129. Rodriguez, L.S. et al. Human myeloid dendritic cells treated with supernatants of rotavirus infected Caco-2 cells induce a poor Th1 response. Cell Immunol. 272, 154-161 (2012).

130. Mesa, M.C. et al. ATGF-beta mediated regulatory mechanism modulates the T cell immune response to rotavirus in adults but not in children. Virology 399, 77-86 (2010).

131. Jaimes, M.C. et al. Frequencies of virus-specific CD4(+) and CD8(+) T lymphocytes secreting gamma interferon after acute natural rotavirus infection in children and adults. J. Virol. 76, 4741-4749 (2002).

132. Rojas, O.L. et al. Human rotavirus specific T cells: quantification by ELISPOT and expression of homing receptors on CD4 + Tcells. Virology 314, 671-679 (2003).

133. Parra, M. et al. Circulating human rotavirus specific CD4 Tcells identified with a class II tetramer express the intestinal homing receptors alpha4beta7 and CCR9. Virology 452-453, 191-201 (2014).

134. Narvaez, C.F. et al. Rotavirus differentially infects and polyclonally stimulates human B cells depending on their differentiation state and tissue of origin. J. Virol. 84, 4543-4555 (2010).

135. Rojas, O.L. et al. Evaluation of circulating intestinally committed memory $B$ cells in children vaccinated with attenuated human rotavirus vaccine. Viral Immunol. 20, 300-311 (2007).

136. Narvaez, C.F. et al. Human rotavirus-specific IgM Memory B cells have differential cloning efficiencies and switch capacities and play a role in antiviral immunity in vivo. J. Virol. 86, 10829-10840 (2012).
137. Serazin, A.C. et al. Improving the performance of enteric vaccines in the developing world. Nat. Immunol. 11, 769-773 (2010).

138. Campbell, D.I. et al. Chronic T cell-mediated enteropathy in rural west African children: relationship with nutritional status and small bowel function. Pediatr. Res. 54, 306-311 (2003).

139. Fagundes Neto, U. et al. Asymptomatic environmental enteropathy among slum-dwelling infants. J. Am. Coll. Nutr. 13, 51-56 (1994).

140. Humphrey, J.H. Child undernutrition, tropical enteropathy, toilets, and handwashing. Lancet 374, 1032-1035 (2009).

141. Korpe, P.S. \& Petri, W.A. Jr. Environmental enteropathy: critical implications of a poorly understood condition. Trends Mol. Med. 18, 328-336 (2012).

142. Lunn, P.G. \& Northrop-Clewes, C.A. Intestinal permeability: update on the enzymatic assay of mannitol. Clin. Chim. Acta. 205, 151-152 (1992).

143. Lunn, P.G., Northrop-Clewes, C.A. \& Downes, R.M. Intestinal permeability, mucosal injury, and growth faltering in Gambian infants. Lancet 338, 907-910 (1991).

144. Stanfield, J.P., Hutt, M.S. \& Tunnicliffe, R. Intestinal biopsy in kwashiorkor. Lancet 2, 519-523 (1965).

145. Lin, A. et al. Distinct distal gut microbiome diversity and composition in healthy children from Bangladesh and the United States. PLoS One 8, e53838 (2013).

146. Adlerberth, I. et al. Intestinal colonization with Enterobacteriaceae in Pakistani and Swedish hospital-delivered infants. Acta. Paediatr. Scand. 80, 602-610 (1991).

147. Nowrouzian, F. et al. Escherichia coli in infants' intestinal microflora: colonization rate, strain turnover, and virulence gene carriage. Pediatr. Res. 54, 8-14 (2003).

148. Azad, M.B. et al. Gut microbiota of healthy Canadian infants: profiles by mode of delivery and infant diet at 4 months. CMAJ 185, 385-394 (2013).

149. Dethlefsen, L., McFall-Ngai, M. \& Relman, D.A. An ecological and evolutionary perspective on human-microbe mutualism and disease. Nature 449, 811-818 (2007).

150. McFall-Ngai, M. Adaptive immunity: care for the community. Nature 445 , 153 (2007).

151. Huber, S., Gagliani, N. \& Flavell, R.A. Life, death, and miracles: Th17 cells in the intestine. Eur. J. Immunol. 42, 2238-2245 (2012).

152. Belkaid, Y., Bouladoux, N. \& Hand, T.W. Effector and memory T cell responses to commensal bacteria. Trends Immunol. 34, 299-306 (2013).

153. Hooper, L.V., Littman, D.R. \& Macpherson, A.J. Interactions between the microbiota and the immune system. Science 336, 1268-1273 (2012).

154. Feng, T. \& Elson, C.O. Adaptive immunity in the host-microbiota dialog. Mucosal Immunol. 4, 15-21 (2011).

155. Chinen, T. \& Rudensky, A.Y. The effects of commensal microbiota on immune cell subsets and inflammatory responses. Immunol. Rev. 245, 45-55 (2012).

156. Kamada, N. \& Nunez, G. Role of the gut microbiota in the development and function of lymphoid cells. J. Immunol. 190, 1389-1395 (2013).

157. Fagarasan, S. et al. Adaptive immune regulation in the gut: T celldependent and T cell-independent IgA synthesis. Annu. Rev. Immunol. 28, 243-273 (2010).

158. Suzuki, K. et al. The sensing of environmental stimuli by follicular dendritic cells promotes immunoglobulin A generation in the gut. Immunity 33 , 71-83 (2010)

159. Mora, J.R. et al. Generation of gut-homing IgA-secreting B cells by intestinal dendritic cells. Science 314, 1157-1160 (2006).

160. Tezuka, H. et al. Prominent role for plasmacytoid dendritic cells in mucosal T cell-independent IgA induction. Immunity 34, 247-257 (2011).

161. Uematsu, S. et al. Regulation of humoral and cellular gut immunity by lamina propria dendritic cells expressing Toll-like receptor 5. Nat. Immunol. 9, 769-776 (2008).

162. Lundell, A.C. et al. Infant B cell memory differentiation and early gut bacterial colonization. J. Immunol. 188, 4315-4322 (2012).

163. Arumugam, M. et al. Enterotypes of the human gut microbiome. Nature 473, 174-180 (2011)

164. Cooper, P.J. et al. Albendazole treatment of children with ascariasis enhances the vibriocidal antibody response to the live attenuated oral cholera vaccine CVD 103-HgR. J. Infect. Dis. 182, 1199-1206 (2000). 
165. Ward, R.L. et al. Serum rotavirus neutralizing-antibody titers compared by plaque reduction and enzyme-linked immunosorbent assay-based neutralization assays. J. Clin. Microbiol. 34, 983-985 (1996).

166. Ward, R.L. et al. Human rotavirus studies in volunteers: determination of infectious dose and serological response to infection. J. Infect. Dis. 154, 871-880 (1986).

167. Ishida, S. et al. Quantification of systemic and local immune responses to individual rotavirus proteins during rotavirus infection in mice. J. Clin. Microbiol., 1996. 34(7), 1694-1700 (1986).

168. Herrera, D. et al. Simultaneous assessment of rotavirus-specific memory B cells and serological memory after B cell depletion therapy with rituximab. PLoS One 9, e97087 (2014).

169. Wei, J. et al. A naturally processed epitope on rotavirus VP7 glycoprotein recognized by HLA-A2.1-restricted cytotoxic CD8 $+\mathrm{T}$ cells. Viral Immunol. 22, 189-194 (2009).
170. Tsang, J.S. et al. Global analyses of human immune variation reveal baseline predictors of postvaccination responses. Cell 157, 499-513 (2014).

171. Li, S. et al. Molecular signatures of antibody responses derived from a systems biology study of five human vaccines. Nat. Immunol. 15, 195-204 (2014).

172. Ahern, P.P., Faith, J.J. \& Gordon, J.I. Mining the Human Gut Microbiota for Effector Strains that Shape the Immune System. Immunity 40, 815-823 (2014).

173. PATH. Exploring New, Non-replicating Rotavirus Vaccines. 2013 15 July 2014]; Available fromhttp://www.path.org/publications/files/ VAC_nrrv_fs.pdf.

174. Vesikari, T. et al. Sustained efficacy of the pentavalent rotavirus vaccine, RV5, up to 3.1 years following the last dose of vaccine. Pediatr. Infect. Dis. J. 29, 957-963 (2010). 